\title{
The art of maintaining everyday life: collaboration among older parents, their adult children, and health care professionals in reablement
}

This article was published in the following Dove Press journal: Journal of Multidisciplinary Healthcare

\author{
Fanny Alexandra Jakobsen' \\ Kjersti Vik' \\ Borgunn Ytterhus ${ }^{2}$ \\ 'Department of Neuromedicine and \\ Movement Science, Faculty of Medicine \\ and Health Sciences, Norwegian \\ University of Science and Technology, \\ Trondheim, Norway; ${ }^{2}$ Department of \\ Public Health and Nursing, Faculty of \\ Medicine and Health Sciences, \\ Norwegian University of Science and \\ Technology, Trondheim, Norway
}

Background: A shift in the work-divide among generations and an ageing population have altered the balance of care and support between families and welfare states. Although state policy has increasingly acknowledged that older adults ageing in place receive support from family members, how adult children perceive their collaboration with their parents and health care professionals in reablement services remains unclear. The aim of this study is to identify how adult children perceive the collaboration between older parents, family members, and health care professionals in reablement services.

Methods: This study has a qualitative research design with a constructivist grounded theory approach. In total, 15 adult children - 6 sons, 8 daughters, and a daughter-in-law, aged 4764 years - whose parents had received reablement services, participated in in-depth interviews. Results: Our findings clarify how children and their older parents' reablement services can collaborate to support how the adult children manage and maintain both their own and their parents' everyday lives. The core category derived from our data analysis was the art of maintaining everyday life, with four subcategories indicating the different dimensions of that process: doing what is best for one's parents, negotiating the dilemmas of everyday life, managing parents' reablement, and ensuring the flow of everyday life.

Conclusion: To promote collaboration among older adults, their children, and health care professionals in reablement, health care professionals need to proactively involve older adults' family members in the reablement processes, particularly because older adults and their children do not always express all of their care-related needs to reablement services.

Keywords: rehabilitation, informal care, primary care, social need, grounded theory, next of kin

\section{Introduction}

Adult children are often incorporated into the everyday life and care of their aging parents, even if their parents receive health care services. However, the relationship between those health care services and the children of older adults can be especially complex because neither party can readily achieve for older adults what the other can; their collaboration has the potential to enhance the care given. ${ }^{1}$ According to the World Health Organization, ${ }^{2}$ health care professionals should involve the families/next of kin of older adults in their care processes as well as keep them informed about their relatives' health conditions, alert them to the health care services available to them, and offer them training and support in care delivery, especially when care-related needs are complex. ${ }^{3}$ However, regarding the exclusive ways in which families or health care services are responsible for the care of older
Correspondence: Fanny Alexandra Jakobsen

Department of Neuromedicine and Movement Science, Faculty of Medicine and Health Sciences, Norwegian University of Science and Technology, NTNU, N-749I, Trondheim 8905, Norway

Tel +477 34l 2798

Email fanny.a.jakobsen@ntnu.no 
adults, the boundaries remain unclear. ${ }^{4}$ In response, we sought to highlight how adult children perceive and experience their collaborations with siblings, parents, and reablement services in the care of their aging parents.

Reablement, also called restorative care in Australia and the United States, refers to health care interventions involving public, community-based rehabilitation programs that aim to aid older adults, regardless of their condition, in performing their everyday activities, maintaining their independence, and maximizing their time out of health care facilities. ${ }^{5-8}$ Older adults who receive reablement services often exhibit decreased functioning or are at risk of such after experiencing an accident or period of illness. ${ }^{9}$ For older adults who have already received care from public health care services, reablement can reduce the need for such services. ${ }^{10}$ For health care professionals, collaborating with the family members of older adults in reablement can present dilemma regarding whether and, if so, when and how collaboration should occur. ${ }^{11}$ Their motives for not involving family members in reablement include wanting to maintain older adults' autonomy and to allow older adults' to decide to what extent, if any, their families participate in their care. By contrast, their motives for collaborating with older adults' families can include needing to gather important information about the older adults', wanting to improve a family's attitude toward reablement by clarifying its purposes, ${ }^{9,12}$ and more generally, striving to ensure that families care for their ageing relatives once reablement ends. ${ }^{11}$ However, to those ends, health care professionals working in reablement services lack systematic approaches for collaborating with the families of their older adults. ${ }^{11}$

When involved in the everyday care of older adults in reablement, family members have reported assuming responsibility for various aspects of care, aiding with their older parents' performance of practical tasks, having to negotiate with their parents, and collaborating with multiple health agencies. ${ }^{13}$ According to Hjelle et a ${ }^{14}$ family members in similar situations want to be involved in the reablement of their older adults, to give and receive information about their care, to be perceived as a resource, and to follow up on the progress of reablement. Family members have earlier expressed satisfaction with receiving direct support from health care professionals in reablement services, whereas family members who were excluded from reablement have expressed that they wanted to receive advice on how to maximize their older parents' independence. In addition, the relatives without contact with reablement worried about their relatives' welfare and their own ability to support them. ${ }^{9}$ Because older adults who may have accepted their decreased functioning but do not want reablement are nevertheless liable to ask family members for help, ${ }^{15}$ at the very least reablement services can guide family members in how to maximize the capabilities and independence of older adults. ${ }^{16}$ Indeed, family members who continued to spend the same amount of time on caring for their older adults after reablement ended reported having learned, from reablement services, systematic ways to meet their older adults' needs. ${ }^{9}$

To date, researchers have observed mixed opinions among older adults, spouses, and children on giving or receiving care in the family, despite often treating all of them as a homogeneous group. ${ }^{9,13,14}$ However, the varying roles of spouses as primary family caregivers to older adults and adult children as secondary ones can affect their abilities and opportunities to support the care of older adults. Whereas adult children who not reside with their parents can be less inclined to offer them support, ${ }^{17,18}$ ones whose parents' spouses have passed away or cannot provide care often take responsibility for caring for their parents. At the same time, adult children who have to share different responsibilities and tasks with siblings in caring for their aging parents are more liable than spouses to experience conflict in the family. ${ }^{19,20}$

Although state policy has increasingly acknowledged that older adults aging in place receive support from family members, how adult children perceive their collaboration with their parents and health care professionals in reablement services remains unclear. Such ambiguity can particularly hinder their collaboration and the organization of reablement services in general, whereas understanding their perspectives on the matter might elucidate at least one aspect of family members' experiences with the reablement of older adults. Further, bettering our understanding of the family members' experiences may reduce their stress and improve the health reablement provided to their parents. The aim of this study is, how adult children perceive the collaboration of older parents, other family members, and health care professionals in reablement services?

\section{Study context}

In Norway, each municipality is responsible for organizing primary public health care services for its residents, such as community-based reablement programs that are delivered in the older adults' own homes. ${ }^{21}$ Although the organization of the reablement programs differs from 
municipality to municipality, an earlier study showed that this has no significant effect on the form of improved performance or satisfaction with daily activities for older adults. ${ }^{22}$ To our knowledge, more than half of all Norwegian municipalities deliver reablement as a commnity-based service. A central aspect of the intervention is asking older adults about "What are important activities in your life that you want to do" instead of "What is the problem you need help with?"23 Reablement is typically intensive and lasts $4-6$ weeks; the interventions directly aid older adults 3-7 days per week with the support of physiotherapists, occupational therapists, registered nurses, or auxiliary nurses, which are often called home trainers.

\section{Material and methods}

To capture family members' experiences with and perceptions of their collaboration with health care professionals working in reablement services, we used a qualitative research design, inspired by a constructivist grounded theory approach. We conducted in-depth interviews with the adult children of older adults in reablement. In-depth interviews provide flexibility in conducting an openended, in-depth exploration of a specific area in which the interviewee has substantial experience.$^{24}$ According to Charmaz, ${ }^{24}$ it is important to be aware of and acknowledge that interviews are influenced by the culture they take place in, the specific historical time, and the social context.

\section{Recruitment}

We recruited adult children by contacting their parents' reablement programs in collaboration with the health care professionals responsible for reablement services and in line with personal protection regulations in Norway. Older adults forwarded information about our study to their children along with our requests for their participation. In some cases, health care professionals received permission from older parents to contact their children by phone. Children who consented to participate responded directly to the first author.

\section{Participants}

A purposeful sampling strategy was applied. This led us to interview a son and eight daughters of older adults who were receiving reablement services. We later determined that there was a need to pursue theoretical sampling, as suggested by Charmaz. ${ }^{24}$ For that reason, we recruited four additional sons. Given our interest in developing a preliminary category that could provide a more nuanced picture of how adult children collaborate with reablement services, a brother of one participant and a sister-in-law of another participant were included in our sample. Our final sample thus included eight daughters, six sons, and a daughter-in-law, all of whom had varied experiences with their parents' reablement processes. Participants ranged in age from 47 to 64 years, whereas their parents were 74-93 years old. Six parents had received reablement services on two to four previous occasions. Fourteen participants were employed with full-time at jobs with regular day shifts or irregular work shifts, some of which required travel. Table 1 provides additional details about the participants.

\section{In-depth interviews}

We conducted in-depth interviews from December 2016 to August 2017. Each participant determined where we would conduct his or her interview, and interview sites included the participant's home or office, a meeting room at a hotel, a library, nursing home or at researcher's workplace. The first author conducted all interviews, which lasted 50-90 mins. The superior interview questions were open-ended, and each interview was flexible in terms of the subordinate questions. In line with Charmaz's ${ }^{24}$ recommendations, analysis commenced after the first interview ended. Because it became apparent after some interviews that the relationship among siblings was important in terms of participants' experiences with and perceptions of their parents' reablement, later interviews posed more questions about the role of siblings as well as about their gender (see Table 2). All interviews was audio-recorded and fully transcribed.

\section{Ethical consideration}

The study was approved by the Norwegian Social Science Data Services (NSD) Project No: 48413. All of the participants received written and oral information about the study and their right to withdraw. Written consent was obtained before the interviews started. In the transcriptions, we anonymized the names of people and places as well as all personal information.

\section{Analysis}

Following Charmaz's ${ }^{24}$ recommendations for analysis, the first author wrote memos after each in-depth interview as well as throughout the different steps of the analysis. The memos were continually reviewed and discussed with the coauthors throughout the analysis. Each memo typically contained a summary of the interview along with 
Table I Characteristics of participants $(\mathrm{N}=15)$

\begin{tabular}{|c|c|c|c|c|c|}
\hline $\mathbf{N}$ & $\begin{array}{l}\text { Participants } \\
\text { (relationship) }\end{array}$ & Age & Sibling(s) & $\begin{array}{l}\text { Parents } \\
\text { (relationship) }\end{array}$ & $\begin{array}{l}\text { Distance to person undergoing reablement (walk- } \\
\text { ing or driving) }\end{array}$ \\
\hline I & Son & $50-59$ & & Mother & $5 \mathrm{~min}$ by car \\
\hline 2 & Daughter & $50-59$ & & Mother & $5 \mathrm{~min}$ by car \\
\hline 3 & Daughter & $50-59$ & & Father & $25 \mathrm{~min}$ by car \\
\hline 4 & Daughter & $50-59$ & & Mother & 5 min by car \\
\hline 5 & Daughter & $50-59$ & Q & Mother & 60 min by car \\
\hline 6 & Daughter & $60-69$ & & Mother & 30 min by car \\
\hline 7 & Daughter & $40-49$ & & Mother & 2 min walking \\
\hline 8 & Son & $50-59$ & Q & Mother & 10 min by car \\
\hline 9 & Daughter & $60-69$ & 0 & Father & 10 min by car \\
\hline 10 & Daughter & $50-59$ & $\sigma^{\prime \prime}$ & Mother & $10 \mathrm{~min}$ by car \\
\hline II & Son & $40-49$ & రం & Father & 15 min by car \\
\hline 12 & Son & $50-59$ & & Mother & 2 min walking \\
\hline 13 & Son & $60-69$ & రారాధ & Mother & 2 min walking \\
\hline 14 & Son & $40-49$ & & Mother & 2 min walking \\
\hline 15 & Daughter in law & $40-49$ & Qீరం & Father in law & $30 \mathrm{~min}$ by car \\
\hline
\end{tabular}

Table 2 Questions during in-depth interviews

\begin{tabular}{|c|c|}
\hline From the in-depth interview guide & $\begin{array}{l}\text { Questions developed during the in-depth } \\
\text { interviews }\end{array}$ \\
\hline $\begin{array}{l}\text { - Can you tell me about what you do together with your parent(s)? } \\
\text { - What is important for your parent(s) daily life? } \\
\text { - What is important for your daily life? } \\
\text { - How do you perceive your parent(s) in their home? } \\
\text { - How is your experience with reablement? } \\
\text { - How do you perceive changes in your parent(s) everyday lives over the past } \\
\text { few years? } \\
\text { - Do they receive any support from the health care service in the } \\
\text { municipality? } \\
\text { - -How does that work? } \\
\text { - Wow does that affect you and your parent every day? }\end{array}$ & $\begin{array}{l}\text { - When the therapist talked to your mother, do you } \\
\text { know if they talked about goals? } \\
\text { - When I have spoken to another participant in this } \\
\text { study it sounds like siblings distribute tasks differently } \\
\text { between them. How is it in your family? } \\
\text { - What do you need from the health care services (for your } \\
\text { - Was it health care professionals in reablement that invited } \\
\text { you or was it you asking to join them in the meeting? } \\
\text { - Did I understand you correctly when you say that your } \\
\text { mother has received reablement twice? } \\
\text { - How do you and your sister share the tasks regarding your } \\
\text { mother? } \\
\text { - What do you think if reablement ask you to support your } \\
\text { parent with training programs? } \\
\text { ment you tell me about your first encounter with the reable- } \\
\text { health care professionals? } \\
\text { - How was it? }\end{array}$ \\
\hline
\end{tabular}

keywords and codes that represented either recurring subcategories or ideas new to the interviewer in the context of the study that subsequent interviews should consider. All three authors participated in the analysis. During the initial coding, the first author read each interview sentence-by-sentence and later developed the initial codes, which ultimately totaled 2,500 in number. NVivo
11 was used in the process of coding. The initial codes were read and discussed by all three authors. The data revealed information about the activities in which the participants, their siblings, and their other family members participated, as well as information about their experiences with and perceptions of traditional homecare, care at hospitals, and care during reablement. 
Table 3 One example of the coding process

\begin{tabular}{|c|c|c|c|}
\hline Initial coding (clustered together) & Focus coding & Sub-category & $\begin{array}{l}\text { Core- } \\
\text { category }\end{array}$ \\
\hline $\begin{array}{l}\text { - It need to be a coordinator in the family } \\
\text { - Daughter tries to get reablement back again } \\
\text { - Daughter hopes the system is working now } \\
\text { - The daughter is the reason why her mother has received reablement } \\
\text { - Mother was tired; daughter fixed reablement } \\
\text { - Daughter asked the hospital and the municipality about rehabilitation } \\
\text { - Daughter contacted reablement; the mother needs to train on getting out } \\
\text { - of bed } \\
\text { - Son needs to be a "pain in the ass" to the local authority's booking office } \\
\text { - When there are more siblings, it is easier to divide the training } \\
\text { - Now that the family knows how reablement works, it is easier for the } \\
\text { - family to intervene and intensify } \\
\text { - The family can start reablement without the formal team } \\
\text { - naughter had to take more responsibility for training if her mother had } \\
\text { - Supporting mother to participate in reablement } \\
\text { - Hiring of a personal trainer }\end{array}$ & $\begin{array}{l}\text { The family as project } \\
\text { manager } \\
\text { Taking over the reable- } \\
\text { ment training } \\
\text { Supporting mother }\end{array}$ & $\begin{array}{l}\text { Managing parent's } \\
\text { reablement }\end{array}$ & $\begin{array}{l}\text { The art of } \\
\text { maintaining } \\
\text { everyday life }\end{array}$ \\
\hline
\end{tabular}

Next, the first author performed focused coding of the participants' perceptions of reablement and collaboration with health care professionals therein. The third author performed focused coding of two of the interviews. Afterward, we compared and discussed our focused codes to ensure the inclusion of all nuances, clustered similar codes, and searched for patterns and variations. While alternating our attention between the data and the codes, we developed four subcategories: doing what is best for one's parents, negotiating the dilemmas of everyday life, managing parents' reablement, and ensuring the flow of everyday life. Lastly, we developed a core category - the art of maintaining everyday life - that was suggested by the subcategories. Table 3 shows an example of the coding process.

\section{Results}

The core category derived from our data analysis was the art of maintaining everyday life, with four subcategories indicating different dimensions of that process: doing what is best for one's parents, negotiating dilemmas of everyday life, managing parents' reablement, and ensuring the flow of everyday life.

\section{The art of maintaining everyday life}

We defined the core category - the art of maintaining everyday life - as the management process that adult children performed to maintain both their and their older parents' everyday lives. For the adult children in our sample, the process included collaborating with one's parents as well as identifying appropriate people in their families or in health care services with whom to collaborate in delivering care to their parents. Our data revealed different dimensions of how such collaboration developed within the family - that is, among parents and siblingsand with reablement services. Participants reported that reablement could be positive for their parents when their parents considered reablement services introduced to be relevant. In such cases, reablement could also support the participants in carrying on with their everyday lives. In any case, however, having older parents who received reablement services presented the participants with an ongoing process of navigating practical and emotional challenges as well as new situations in their parents' lives.

\section{Doing what is best for one's parents}

The adult children described beginning to collaborate with their siblings and health care professionals in reablement services upon observing their parents' struggle to pursue their everyday lives. Concerned about how their aging parents would manage in their everyday lives, they first sought ways to help their parents cope at home. An aspect of the first subcategory-doing what is best for one's 
parents - was thus the children's conflict of respecting their parents' wishes to live at home while being honest about the fact that their parents needed practical support. For example, to accommodate their parents' declining functioning, participants sometimes had to make physical adjustments to their parents' homes. Several participants explained that collaborating with reablement services was useful because service representatives offered input on how their parents' houses could be adapted to make them safer for their parents. One son recalled his reaction when health care professionals in reablement service advised him in that way:

We [my family] got advice about what we should do with the furniture, and I thought that was great. She [the health care professional] said, "I won't tell you what to do, but here's what you could do," and we did those things. It took us a day, and we later bought a new TV table because the old one had become an obstacle [for my mother], and now she can pass it with her walker, and we also removed some carpets. We rearranged the furniture so that now they both [my mother and father] have a place to sit, and she has space for her walker, and it worked. It [adjustment of the home] had never crossed my mind before, but it's great.

Several participants described how they had adapted their parents' domestic lifestyle - for example, by hiring a cleaning agency and by helping to remodel their houses - in order to facilitate their parents' daily activities. Most of their parents had expressed satisfaction with and gratitude for what their children had done for them. Other participants, however, talked about experiencing conflicts with their parents or siblings, if not both, about what would be best for the parents and what types of support they needed. Some parents, for instance, disagreed about changes that their children had planned for their homes. One daughter stated:

The problem isn't about offering to do things and make adjustments—really, that's not the point—but she [my mother] wants to manage on her own and have things the way that they've always been and to make do with that. But she really needs to understand that she needs to accept some help.

Conflicts regarding the kinds of support that declining parents needed was thus another aspect of doing what is best for one's parents. Tensions related to parents' wishes to stay at home versus their incapacity to do so presented challenges for participants. In families with multiple adult children, participants often formed alliances with their siblings and collaborated with them to convince their parents to accept changes in their homes. In one family, the children agreed to remove blankets from the kitchen after their older parent's hospitalization; in another, negotiations were necessary between the children about whether and, if so, how their parents' home needed modification. By contrast, in attempting to maintain their everyday lives and act in their parents' best interests, some participants, especially ones with siblings who lived far away received no support from their siblings. In consequently taking full responsibility for coordinating their parents' reablement services and without involving their siblings.

\section{Negotiating dilemmas in everyday life}

Whereas doing what was best for one's parents typically entailed practical challenges, challenges captured by the second subcategory - negotiating dilemmas in everyday lifecomplicated how participants maintained their relationships with their older parents and collaborated with them on a daily basis. For some participants, a major dilemma was persuading parents to follow the advice of health care professionals in reablement services versus accepting that their parents wanted to discontinue receiving the services even if it would decrease their daily functioning. In response to that dilemma, participants sought to encourage their parents to continue receiving reablement services and to follow the advice of health care professionals. They believed that reablement could not only increase their parent's self-efficacy and daily functioning but also represent an opportunity for their parents and themselves to maintain their everyday lives. When participants contacted reablement services or tried to convince their parents to make contact, they made it clear to their parents that they should accept any offer from the services. When their parents resisted receiving such services, because they either lacked information about what the services could provide or simply felt full of years and wanted to rest, participants reported watching their parents grow weaker due to their reduced functioning. One son described his mother's situation:

She hasn't liked it [reablement], but she likes it when she recovers. She seems to lack the ability to reflect on what happened during the previous month-where she was, where she was going, what had happened-and learn from it. Quite the opposite. She recalls how they [reablement professionals] shouldn't enter her house and force her to do things... . I was afraid that they would simply stop. Because if she says, "I don't want you here," then they have to leave according to the law, even if she doesn't understand what's best for her. 
Parents' pain and lack of motivation were other factors of their resistance to receiving reablement services. One daughter explained the uselessness of trying to convince her mother to be more active:

Once she [my mother] said, "Oh well. I better try to do what they [reablement professionals] say." But once they left her house, she was back on the couch. There was some pressure, but it's okay that there are people in her house. She simply needs to do something. She really needs to get her act together. She needs to look in the mirror. Because she's gone downhill really far.

Participants generally struggled with the dilemma of convincing parents to participate in reablement versus allowing them to abstain. Recognizing that their parents' passivity only deteriorated their functioning, they particularly struggled with respecting their parents' wishes while wanting to do their best to improve their parents' situations. "

Some participants stressed the importance of having highly competent health care professionals who could collaborate with older people who have withdrawn from their previously active lives. They also emphasized the value of collaborating with a multidisciplinary team of reablement professionals, hospital employees, general practitioners, and their family members. Invariably, participants had to clarify to their parents the purpose of reablement services and explain that such services could support both parents and adult children in maintaining their everyday lives.

\section{Managing parents' reablement}

The third subcategory - managing parents' reablementcaptured how participants felt primarily responsible for the delivery of their older parents' reablement services. Such responsibility partly stemmed from participants' experience with caring for their parents. Because most participants had assisted their parents for several years before they commenced reablement, they had experiences with trying to collaborating with their parents and health care professionals, if not also siblings. . One participant explained, "The task [taking care of my parents] has grown as time has passed ... I've been working with sick parents since I moved back here a few decades ago."

Another aspect of managing parents' reablement was that the adult children had often assumed responsibility for initiating collaboration with reablement services. Some participants reported dilemmas upon contacting the services, however; they did not want health care professionals to consider them to be pushy or overbearing yet also needed to ensure that their parents received the necessary support. After all, their and their parents' everyday lives were at stake. One participant described the feeling:

Since I'm not currently married and don't have siblings, I imagined that it [responsibility for my parent's] might easily become a real burden to me, especially because I wasn't familiar with the structure and systems of public services. So, it was likely that I would eventually become a "pain in the ass" to the local authority's booking office. I would have to be.

That quotation captures how some participants felt when initiating new services for their parents' emerging needs and following up on services for existing ones. Participants appreciated face-to-face encounters and regular phone calls with health care professionals in reablement service, because talking to professionals and being able to call them in the case of care-related doubts made their everyday lives easier.

A third aspect of the subcategory was that, for adult children, managing their parents' reablement was a strategy for mitigating their parents' reduced daily functioning. Some participants observed that because local services had highly limited resources, they would have to assume responsibility for their parents' care and making arrangements in the family to that end. One son recounted his experience:

I've accepted that there are limited resources [assistance from local services]... . I think it's appropriate that children or relatives help more than public services. I admit that we [my family] has some particular ways of doing things... . As my mother says, "We can arrange this ourselves." And I probably think that's okay. It's good that there are [reablement] programs, and there have to be, because experts are necessary, just not all of the time. You try to "roll up your sleeves" and arrange things, but I can see from my sister's experience that it's not easy to help when life is so hectic. But I have to say that I'm generally satisfied with how we've managed.

Although he and other participants have assumed responsibility for their parents' care and appreciate that reablement services are available, they also expressed wanting such care to be tailored to their parents' functioning and needs so that their families can maintain their everyday lives. By informing and guiding their next of kin, some participants believed that they could later contribute to 
their parents' training programs when necessary. For other participants, however, assuming responsibility for their parents' care was problematic. As one participant highlighted, being in charge of meeting parents' needs can conceal parents' needs from health care professionals, which can prevent them from receiving the services that they need.

\section{Ensuring the flow of everyday life}

The fourth and final subcategory-ensuring the flow of everyday life - captured how participants considered that reablement services could affect the flow of their everyday lives. One aspect of that dynamic related to the emotional dimension of supporting and motivating parents to be physically active. One daughter explained:

I think it [the reablement program] was great-really super. It was a great program, and the trainer was so nice, and they [reablement professionals] got the training going... . If you're the next of kin, you tell them [parents] it's important to do the workout and that they have to walk... . It's something else when others say the same thing and you see that it has more effect.

Such a feeling was common among several participants, which could indicate that they commonly experienced encouraging their parents to be active.

Another aspect of ensuring the flow of everyday life was temporal. After all, adult children's everyday lives are typically busy; most participants worked full-time and cared for their own children or grandchildren along with their older parents or parents-in-law. One participant imagined:

If she [my mother] had not received it [reablement services], I would have felt much more sharply that it was my job to give her training and be encouraging, which is difficult when you're the child... . That would've been a completely different situation for me.

That the reablement services had trained her mother meant that she and her siblings could support her mother in completing other tasks.

A final aspect of ensuring the flow of everyday life related to adult children whose parents lived together, because the other parent often also had his or her unique needs or kind of reduced functioning. Some participants therefore expressed that health care professionals working in reablement services need to recognize that older adults often put on a brave face for health care professionals and that siblings often experience parents' needs differently.
By the same token, participants were interested in collaborating with the services and learning more about how they perceived their parents. To that end, they indicated that health care professionals in reablement had more evidence of their parents' functioning than professionals in home-care services because the former more regularly visited their parents and stayed longer when they did. However, because their parents' improvement was typically fleeting, participants underscored the need for more proactive follow-up and planning for the future, especially given their awareness that new situations in their parents' everyday lives would arise.

\section{Discussion}

Our findings revealed how the art of maintaining everyday life involves balancing the wishes and needs of older parents against what their adult children as well as reablement and other health care services believe to be in their best interests. Although our findings illuminate that adult children want to do what is best for their parents, some children perceived a dilemma in persuading their parents to follow the advice of reablement services versus accepting their parents' wishes to withdraw from such services, even if doing so meant their reduced ability to continue living in their homes. Our sub category thus indicate that doing what is best for one's parents can be perceived as normative, which both partly supports and nuances current understandings of the art of balancing the social needs of adult children and their older parents. In what follows, we discuss our findings with reference to Bradshaw's ${ }^{25}$ different types of social needs: normative needs, felt needs, expressed needs, and comparative needs.

\section{Normative need}

Normative need refers to societal values that reflect the judgment of professionals and policymakers and that can change according to context. ${ }^{25}$ Although adult children in our sample seemed to have internalized the policy that it is best for older adults to live in their homes for as long as possible, policymakers, health care professionals, older adults, and their family members often have different understandings of what constitutes optimal support for older adults still living at home. ${ }^{18,26-29}$ In particular, health care professionals often judge individuals' needs according to what they are able to provide, ${ }^{18,30}$ which cause tension given the sometimes divergent interests of older adults, their family members, and health care professionals. ${ }^{14}$ 


\section{Felt need}

Felt need refers to an individual's subjective perceptions of what he or she needs. ${ }^{25}$ Our findings showed that adult children were generally enthusiastic about the possibility of accessing reablement services to support their older parents both mentally and physically after illness and periods of inactivity. That result corroborates the findings of Moe and Brinchmann, ${ }^{13}$ as well as of Hjelle et al, ${ }^{14}$ who have observed the advantage of having a non-family member support older adults in increasing their self-efficacy in everyday life. By some contrast, Heid et $\mathrm{al}^{31}$ have observed that adult daughters often defined their parents' best interests according to their personal assumptions. If parents disagreed with their daughters' opinions, then frustration, tension, and conflict in the parent-child relationship resulted. In our findings we have also similar findings, however our findings illuminate that even though both daughters or sons disagreed with their parents opinions, most of them still accepted if their parent resisted receiving reablement. Although the adult children in our study argued from their own perceptions reablement is a service that could benefit their aging parents. That finding warrants reference to Bradshaw, ${ }^{25}$ who has posited that an individual's perceived lack of knowledge about a service or reluctance to admit a loss of personal autonomy can limit the felt need to accept help from the service. Possibly, older adults do not want to receive reablement services because their benefits have not been clearly explained, they perceive that the services cannot be tailored to meet individual needs, or they simply do not want to receive any public services at home. Our findings suggest that, in such cases, open dialogue among older adults, their adult children, and reablement services is therefore crucial.

Several participants reported supporting their older parents for years before seeking help from reablement services. That finding supports earlier results that family members are more involved in supporting older parents than health care professionals believe. ${ }^{26,32}$ Sørbye et al ${ }^{33}$ have highlighted that care from relatives is pivotal to how long older adults with heavy care burdens can stay at home. Our findings nevertheless indicate that adult children seek to collaborate with health care professionals; participants especially reported wanting feedback on how health care professionals perceive and assess their parents' functioning at home, which can be particularly useful when siblings assess the needs of their parents differently.
According to Bjasinsky, ${ }^{34}$ adult siblings may experience mixed emotions upon realizing that their parents are becoming less independent and need more physical, emotional, and moral support from caregivers. In our study, participants demonstrated that trend by repeatedly describing changes in their parents' ability to function and how they affected the everyday lives of family members. The adult children therefore wanted their parents to receive reablement services for longer and for health care professionals to make follow-up visits to their parents after intensive interventions end. That finding aligns with the results of Hjelle et al, ${ }^{14}$ who observed that families prefer extended follow-up on their older members after reablement.

\section{Expressed need}

Bradshaw $^{25}$ characterizes expressed need as arising from felt needs that individuals ultimately express. However, adult children do not always express such needs regarding the care of their older parents to health care professionals in reablement services. Naidoo and Wills ${ }^{30}$ have stressed that, more often than not, individuals who might benefit most from health care services are least likely to take advantage of those services. Our results revealed that adult children most often assumed responsibility for contacting reablement services or for monitoring their progress when their parents were receiving the services. However, several participants remained uncertain about what they could realistically expect from reablement services and reported that the distribution of responsibility for caring from their parents can be unclear, particularly in relation to follow-up services. The latter problem could stem from the failure of health care professionals and family members to discuss how they should share such responsibility. ${ }^{32}$ That failure could relate to how health care professionals working in reablement services are often uncertain about how to proceed in administering services, given their belief that older adults are responsible for involving their families, even if the professionals wanted more extensive collaboration with the families. ${ }^{11}$ According to Tønnessen and Kassah, ${ }^{4}$ boundaries of caring for older adults are vague when it comes to which responsibilities are the family's and which are the municipal health care service's. Even so, policy recommends focusing more on collaboration with families so that they can continue to support their older members. ${ }^{2}$ To clearly delineate responsibilities, Wittenberg et $\mathrm{al}^{32}$ have 
underscored the need for health care professionals to form good relationships with the family members of older adults'. Another finding of our study that may influence families' collaboration with reablement services was that adult children perceived that their parents put on a brave face to health care professionals, who should therefore be aware of that tendency when serving older adults in reablement.

\section{Comparative need}

According to Bradshaw, ${ }^{25}$ comparative need refers to the difference in need among similarly afflicted groups seeking services. Although we did not perform a comparative study of different groups of older reablement service users, we argue that spouses of such users could be an eligible group. Participants in our sample experienced that when one parent received reablement services, the other parent often could benefited as well. They also recommended that health care professionals consider both parents in reablement processes. We suggest that health care professionals in reablement services thus assume greater responsibility for enhancing collaboration with families by inviting them to coordination meetings and assuming the role of guide or adviser instead of just give attention to one part of the couple. Put differently, professionals should give families genuine opportunities to decide what and how they want to contribute to the care of their older members.

\section{Methodological considerations}

The findings in this study clarify how some adult children support their parents later in life and experience encounters with reablement services. Based on the principles of grounded theory, our study afforded an opportunity to observe emerging patterns and ideas during data collection and analysis and to alter our methods in response. ${ }^{24}$ To ensure the trustworthiness of our data, we used theoretical sampling in six of the last interviews. However, this study might have some limitations because the findings are limited in its scope with regards to the number and representation of the adult children and the daughter-in-law who participated and in terms of the period of time in which the study was conducted.

Another possible limitation of the study, and hence transferability of findings involved, is that the participants in this study mainly lived close to their parents, mostly had good relationships with them, and were the ones that actively supported their parents. It might be possible that adult children with greater care burdens or who lived farther away might have been less likely to respond. Further, it might be that their view of collaboration with their parents, siblings, and health care professionals in reablement services could have been different than our findings. Additional studies ought to illuminate the perspectives of adult children who live far away from their parents. We are also aware that when some families experience relationship conflicts, some adult children might consider it best to not get involved in caring for their aging parents. A third issue is the potential discrepancy in how adult children and their parents may see the parents' situation and needs. In this study, we just illuminated the children's construction and perspectives; in the future, researchers should examine older adults' perceptions of the collaboration between families and such services.

\section{Implications and conclusion}

Our findings shed light on how adult children who live close to their own parents perceive their own everyday lives and their parents' reablement processes, as well as highlight the potential importance of collaboration between siblings, parents, and health care professionals in reablement.

Such findings could be particularly important when determining the best means of support for older adults. Although the general goals of reablement are to increase the independence of older adults and reduce the expenses of municipal services, ${ }^{10}$ policymakers, health care professionals, older adults, and their family members often have different understandings of what constitutes optimal support for older adults. ${ }^{18,26-29}$ Health care professionals need to be aware of different perspectives on social needs, for older adults and family members do not always express their needs. We recommend that reablement services support families in focusing on dilemmas about values, as well as promote the safety and autonomy of older adults, which may influence how they and their family members can maintain their everyday lives. ${ }^{35}$ In that way, consensus might be reached regarding what means of support for older parents are best for them and their adult children.

Last, health care professionals need to recognize that adult children can face complex dilemmas in supporting their parents, since familiar bonds can complicate the distribution of care-related roles and responsibilities. Adult children who have supported their parents before 
and after reablement cannot merely withdraw afterward in the same way that health care professionals can. It is important that health care professionals in reablement services recognize that dynamic and proactively initiate communication with older adults and their families. ${ }^{32}$

\section{Acknowledgments}

We wish to thank the participants, all of whom shared their experiences with us, and their parents, all of whom allowed their children and children-in-law to participate in this study. We also wish to thank the health care professionals who recruited participants for our research.

\section{Disclosure}

The authors report no conflicts of interest in this work.

\section{References}

1. Büscher A, Astedt-Kurki P, Paavilainen E, Schnepp W. Negotiations about helpfulness: the relationship between formal and informal care in home care arrangements. Scand J Caring. 2011;25(4):706-715. doi:10.1111/j.1471-6712.2011.00881.x

2. World Health Organization. World Report on Ageing and Health. Geneva: World Health Organization; 2015.

3. World Health Organization. Integrated Care for Older People: Guidelines on Community-Level Interventions to Manage Declines in Intrinsic Capacity. Geneva: World Health Organization; 2017.

4. Tønnessen S, Kassah BLL. Pårørende I Kommunale Helse- Og Omsorgstjenester, Forpliktelser Og Ansvar I Et Utydelig Landskap. [Next of Kin in Municipal Health and Care Services, Obligations and Responsibilities in an Ambigous Landscape]. Oslo: Gyldendal Akademisk; 2017. Norwegian.

5. Cochrane A, McGilloway S, Furlong M, Molloy DW, Stevenson M, Donnelly M. Home-care re-ablement services for maintaining and improving older adults' functional independence [review]. Cochrane Database Syst Rev. 2013;11:CD010825.

6. Aspinal F, Glasby J, Rostgaard T, Tuntland H, Westendorp RG. Reablement: supporting older people towards independence. Age Ageing. 2016;45(5):1-5. doi:10.1093/ageing/afw094

7. Glendinning C, Newbronner E. The effectiveness of home care reablement: developing the evidence base. J Integr Care. 2008;16 (4):32-39. doi:10.1108/14769018200800031

8. Tuntland H, Ness NE. Hverdagsrehabilitering. [Reablement] 1 ed. Oslo: Gyldendal Akademisk; 2014. Norwegian.

9. Glendinning C, Jones K, Baxter K, et al. Home Care Re-Ablement Services: Investigating the Longer-Term Impacts (Prospective Longitudinal Study). York: Social Policy Research Unit, University of York; 2010.

10. Ebrahimi V. Reablement: shifting minds. In: Ebrahimi V, Chapman HM, editors. Reablement Services in Health and Social Care: A Guide to Practice for Students and Support Workers. London: Macamillan Education; 2018:1-31.

11. Jakobsen FA, Vik K. Health professionals' perspectives of next of kin in the context of reablement. Disabil Rehabil. 2018;15:1-8. doi:10.1080/09638288.2018.1450452

12. Rabiee P, Glendinning C. Organisation and delivery of home care reablement: what makes a difference? Health Soc Care Community. 2011;19(5):495-503. doi:10.1111/j.1365-2524.2011.01010.x
13. Moe C, Brinchmann BS. Optimising capacity: a service user and caregiver perspective on reablement. Grounded Theory Rev. 2016;15(2):20-40.

14. Hjelle KM, Alvsvåg H, Førland $\mathrm{O}$. The relatives' voice: how do relatives experience participation in reablement? A qualitative study. J Multidisc Healthc. 2016;20(10):1-11. doi:10.2147/JMDH. S122385

15. Winkel A, Langberg H, Wæhrens EE. Reablement in a community setting. Disabil Rehabil. 2015;37(15):1347. doi:10.3109/ 09638288.2014.963707

16. Wilde A, Glendinning C. 'If they're helping me then how can I be independent?' The perceptions and experience of users of home-care re-ablement services. Health Soc Care in the Community. 2012;20 (6):583-590. doi:10.1111/j.1365-2524.2012.01072.x

17. Robinson K, Austin JK. Wife caregivers and supportive others perceptions of the caregivers' health and social support. Res Nurs Health. 1998;21(1):51-57. doi:10.1002/(ISSN)1098-240X

18. Stoltz P, Udén G, Willman A. Support for family carers who care for an elderly person at home: A systematic literature review. Scand J Caring S. 2004;18(2):111-119. doi:10.1111/j.1471-6712.2004.00269.x

19. Tatangelo G, McCabe M, Macleod A, Konis A. I just cant please them all and stay sane: adult child caregivers experiences of family dynamics in care-giving for a parent with dementia in Australia. Health Soc Care Community. 2018;26(3):e370-e377. doi:10.1111/hsc.12534

20. Strawbridge WJ, Wallhagen MI. Impact of family conflict on adult child caregivers. Gerontologist. 1991;31(6):770-777.

21. Ministry of Health and Care Services. Ansvar Og Meistring: Mot Ein Heilskapleg Rehabiliteringspolitikk: St.Meld. Nr 21. [Responsibility and Coping: Towards a Holistic Rehabilitation Policy]. Oslo, Norway: Ministry; 1999. Norwegian.

22. Langeland E, Førland O, Aas E, et al. Modeller for Hverdagsrehabilitering-En Følgeevaluering I Norske Kommuner. Effekter for Brukerne Og Gevinster for Kommunene? [Models for the Reablement-A Follow-Up Evaluation in Norwegian Municipalities. Impact on Users and Benefits for the Municipalities?]. Bergen: Center for Care Research, West; 2016. Norwegian.

23. Fürst H. Fra Passiv Mottaker Til Aktiv Deltager. [From Passive Recipient to Active Participant]. Oslo: The Norwegian Association of Local and Regional Authorities; 2014. Norwegian.

24. Charmaz K. Constructing Grounded Theory. Los Angeles: Sage; 2014.

25. Bradshaw J. Taxonomy of Social Need. 1972. In: McLachlan G, editor. Problems and Progress in Medical Care: Essays on Current Research, 7th Series. London: Oxford University Press; 1979:71-82.

26. Vik K, Nyård L, Lilja M. Perceived environmental influence on participation among older adults after home-based rehabilitation. Phys Occup Ther Geriatr. 2007;25(4):1-20. doi:10.1080/ J148v25n04_01

27. Nolan M, Davies N, Grant G. Working with Older People and Their Families. UK: McGraw-Hill Education; 2001.

28. Ministry of Health and Care Services. Meld. St. 26 (2014-2015). Fremtidens Primcerhelsetjeneste - Noerhet Og Helhet. [The Primary Health and Care Services of Tomorrow Localised and Integrated]. Oslo, Norway: Ministry; 2014. Norwegian.

29. Bonder BR, Dal Bello-Haas V. Functional Performance in Older Adults. Philadephia: FA Davis; 2008.

30. Naidoo J, Wills J. Foundations for Health Promotion. 4 ed. Amsterdam: Elsevier; 2016.

31. Heid AR, Zarit SH, Van Haitsma K. Older adults' influence in family care: how do daughters and aging parents navigate differences in care goals? Aging Ment Health. 2016;20(1):46-55. doi:10.1080/ 13607863.2015.1049117

32. Wittenberg Y, Kwekkeboom R, Staaks J, Verhoeff A, Boer A. Informal caregivers' views on the division of responsibilities between themselves and professionals: A scoping review. Health Soc Care Community. 2017;26:e460-e473. 
33. Sørbye LW, Sverdrup S, Pay BB. Should frail older adults be in longterm care facilities? J Multidiscip Healthc. 2018;11:99. doi:10.2147/ JMDH.S155372

34. Bjasinsky M. Family dynamics: influencing care of the older adult. Act Adapt Aging. 1997;22(4):65-72.
35. Hogstel MO, Gaul AL. Safety or autonomy an ethical issue for clinical gerontological nurses. J Gerontol Nurs. 1991;17(3): 6-9.

\section{Publish your work in this journal}

The Journal of Multidisciplinary Healthcare is an international, peerreviewed open-access journal that aims to represent and publish research in healthcare areas delivered by practitioners of different disciplines. This includes studies and reviews conducted by multidisciplinary teams as well as research which evaluates the results or conduct of such teams or healthcare processes in general. The journal covers a very wide range of areas and welcomes submissions from practitioners at all levels, from all over the world. The manuscript management system is completely online and includes a very quick and fair peer-review system. Visit http://www.dovepress.com/testimonials. php to read real quotes from published authors. 